\title{
Uncertainties in dissolved organic carbon load estimation in a small stream
}

\author{
Olaf Büttner ${ }^{1, *}$, Jörg Tittel ${ }^{2}$ \\ ${ }^{1}$ Helmholtz Centre for Environmental Research - UFZ, Department Aquatic Ecosystems Analysis and Management, Brückstr. 3a, \\ 39114 Magdeburg, Germany. \\ ${ }^{2}$ Helmholtz Centre for Environmental Research - UFZ, Department Lake Research, Brückstrasse 3a, 39114 Magdeburg, Germany. \\ * Corresponding author. Tel.: +49 391 8109651. Fax: +49 391 8109150. E-mail: olaf.buettner@ufz.de
}

\begin{abstract}
Dissolved organic carbon (DOC) transported by rivers represents an important link between carbon pools of terrestrial and oceanic ecosystems. However, it is unclear how frequent DOC must be sampled to obtain reasonable load estimates. Here, we used continuous records of the specific UV absorption coefficient (SAC) and discharge from a headwater stream at the Ore Mountains (Germany) to calculate load errors depending on DOC sampling frequency. SAC was used as a proxy for DOC. The results show that the load was underestimated by $13-19 \%$ with monthly, 10-13\% with bi-weekly and 7-9\% with weekly DOC samplings, respectively. We conclude that collecting additional data from high discharge events decrease the error significantly.
\end{abstract}

Keywords: Dissolved organic carbon; Sampling strategy; UV absorption; Discharge; Yield; Reservoir.

\section{INTRODUCTION}

Dissolved organic carbon (DOC) represents one of the most recycled actively pools of reduced carbon on earth. The amount of DOC in marine and limnetic systems is comparable to that of carbon in living plants and higher than that of atmospheric $\mathrm{CO}_{2}$. Riverine DOC links terrestrial and oceanic ecosystems (Battin et al., 2008). For accurate estimations of DOC load, continuous high-quality records of discharge are a prerequisite. However, it is unclear how many DOC samples are required to estimate the load of a specific time period within given error ranges.

To quantify the error for load estimation associated with a specific sampling frequency, we need to define a "true" load as a reference. Here, the number of samples must be as high as possible, although, it will always be limited by the sampling effort (e.g. one sample each day for one year). The derived true load still contains other errors not related to temporal variability and not considered here, such as the analytical error. For example, Johnes (2007) studied the uncertainties associated with sampling frequency for a data set of 17 UK catchments covering a total of 39 water years with daily discharge and daily phosphorous concentrations. He recommended a stratified sampling program with daily sampling on the 35 highest flow days in the year, combined with weekly sampling during the remainder of the year. This sampling program design returns load estimates with a low bias and imprecision. Johnes (2007) concluded that uncertainty increases at all sampling frequencies as river regimes becomes more extreme. Rode and Suhr (2007) analysed data from the Elbe River (Germany). They stated that for mesoscale river catchments reasonable annual dissolved load calculations can be achieved using bi-weekly sample frequencies. In many situations, the concentrations of most dissolved substances in river water will vary over a limited range. The use of infrequent samples may introduce only relatively limited errors into load assessments, if accurate information on water discharge is available. In case of particulate- or sediment associated compounds, however, concentrations may vary over several orders of magnitude, particularly during flood events. Rode and Suhr (2007) concluded that uncertainties associated with load estimates based on infrequent samples will decrease with increasing size of catchment.
With respect to DOC load estimation, Cooper and Watts (2002) compared three different methods. They used weekly DOC concentration and daily discharge measurements aggregated from $15 \mathrm{~min}$ records from River Severn (UK). Depending on the estimation method, differences between $25 \%$ and $75 \%$ appeared for years with additional data, showing the significant effect of a small number of extra samples. Because the additional samples were taken at high discharges when DOC concentrations were high, the estimated loads with weekly data strongly underestimated the true load. A similar result revealed a recent study in a small head water catchment in British Columbia (Canada) where DOC load derived from weekly measurements were found to underestimate load by as much as $30 \%$ compared to DOC load calculated from high-frequency data (Jollymore et al., 2012).

The aim of this study was to estimate the error associated with a given DOC sampling frequency in order to derive a reasonable sampling strategy to calculate the DOC load of a small stream.

\section{STUDY AREA AND DATA}

The stream Wiltzsch drains a small catchment of $1.72 \mathrm{~km}^{2}$ at the comb of the Ore maintains (Germany) before entering the drinking water reservoir Carlsfeld. The whole catchment is situated in a conservation area without roads or urban areas. Long-term mean annual discharge (1913-2005) amounted to $0.053 \mathrm{~m}^{3} \mathrm{~s}^{-1}$ (970 mm/year; Grunewald and Scheithauer, 2010). Annual maxima typically ranged from $0.4-1.3 \mathrm{~m}^{3} \mathrm{~s}^{-1}$. Maxima can occur during spring snow melt or later in the season. The catchment is mainly covered by forest (spruce), the bedrock consists of granite covered by podsol layers and peatland (Grunewald et al., 2011). We used continuous in-stream measurements of the specific UV-light absorption coefficient (SAC, $254 \mathrm{~nm}$ wave length, measured every 15 minutes). The SAC data was obtained using an automatic probe "UVAS plus sc 5 mm" (Hach-Lange, Düsseldorf, Germany; Hach-Lange, 2012). SAC was applied as proxy for DOC (Grayson and Holden, 2012; Jollymore et al., 2012) which was based on the characteristic of DOC to attenuate UV light efficiently. We converted SAC to DOC concentration assuming that $6 \mathrm{~m}^{-1}$ units SAC 
corresponded to $1 \mathrm{mg} \mathrm{L}^{-1}$ DOC. The specific value of this conversion has no significance for the error calculations. However, the analysis was based on the reasonable assumption that both, DOC and SAC exhibited the same temporal variation. Discharges were measured every 15 minutes in a well-defined masoned channel before a thin-plate notched weir. For error analyses, daily mean DOC concentrations and daily mean discharges were derived for the years 2009-2011.

\section{BIAS OF LOAD ESTIMATION}

The annual reference "true" load $\left(\mathrm{F}_{\text {true }}\right)$ was calculated by daily discharges and daily concentrations according to Eq. (1):

$$
F_{\text {true }}=K \sum_{i=1}^{365} c_{i} Q_{i},
$$

where $K$ is conversion factor to account for the period of load estimation and measurement units, $c_{i}$ is DOC concentrations derived from SAC, and $Q_{i}$ is measured daily discharge.

For a monthly sampling rhythm, annual loads were calculated using measured DOC data from the first day of each month and interpolated values in between. For discharges, only measured data were included. We continued with the DOC data of the second day and then of the third day and so on until thirty annual loads were obtained. In addition, fourteen annual loads for a biweekly and seven loads for a weekly sampling rhythm were derived according to Eq. (2).

$$
F_{j, y e a r}=K \sum_{i=1}^{365} c_{i}^{i n t} Q_{i},
$$

where $F_{j, \text { year }}$ is $j$-th variant of load estimation for $j=1, \ldots, N$ and year $=\{2009,2010,2011\}, c_{i}^{i n t}$ daily concentrations, linearly interpolated between two considered samples, and $N 30$ (monthly), 14 (bi-weekly), 7 (weekly).

The relative errors $\varepsilon$ were estimated as the quotient of an annual load and the true load:

$$
\varepsilon_{j, \text { year }}=\frac{F_{\text {true }}}{F_{j, \text { year }}} .
$$

The mean of the relative errors $\bar{\varepsilon}$ was taken as a measure of accuracy, and the standard deviation $s$ gave a measure of precision. The root-mean-square error RMSE was used as evaluation criterion with combines accuracy and precision (Moatar and Meybeck, 2005):

$R M S E=\sqrt{\bar{\varepsilon}^{2}+s^{2}}$.

The results show that the true load was underestimated by 13 to $19 \%$ in all three years if a monthly sampling strategy was used (Table 1). This comparatively low error range was based on the fact that discharges exhibited higher temporal variations than DOC. In addition this underlines the importance of high quality discharge measurements. The calculated daily load may be differing considerably from the true load (Fig. 1). The accuracy of estimation increased with increasing sampling interval. Precision ranged from 2 to $12 \%$ and increased (the variances becomes smaller) with accuracy due to shorter sampling intervals. Both results are reflected in the calculated RMSE. With additional sampling effort, the RMSE decreased considerably. For the presented case study, the loads were underestimated, mainly because DOC concentration increased during high discharges. Vidon et al. (2009) investigated two small catchments different in land use (mainly agriculture, small contribution of forest) compared to Wilzsch and also found that loads were underestimated using three different load estimation methods. The authors investigated the impact of sampling strategy on solute loads including DOC and concluded that increasing sampling frequency only slightly improves the accuracy of solute load estimates but improves the precision of load calculations. Tian et al. (2012) studied the influence of environmental factors (stream flow, land cover type, vegetation density, and drainage area) on the DOC export from an urban watershed. They demonstrated that all factors except vegetation density are particularly strong predictors for DOC dynamics. Regarding the sampling strategy, they concluded that field data measured one day each month does not provide sufficient information for modeling in-stream DOC concentration.

\section{CONCLUSION}

We suggest for the Wilzsch catchment and catchments with comparable land use properties and similar hydrological conditions that either a bi-weekly or a monthly sampling strategy

Table 1. Accuracy, precision and RMSE of SAK load estimates for years 2009 to 2011 (Wilzsch).

\begin{tabular}{lcccc}
\hline & Sampling & 2009 & 2010 & 2011 \\
\hline Accuracy (\%) & monthly $(\mathrm{n}=30)$ & -13 & -17 & -19 \\
& bi-weekly $(\mathrm{n}=14)$ & -10 & -14 & -9 \\
weekly $(\mathrm{n}=7)$ & -7 & -10 & 12 \\
Precision (\%) & monthly $(\mathrm{n}=30)$ & 6 & 8 & 6 \\
& bi-weekly $(\mathrm{n}=14)$ & 7 & 6 & 5 \\
weekly $(\mathrm{n}=7)$ & 2 & 2 & 23 \\
RMSE (\%) & monthly $(\mathrm{n}=30)$ & 14 & 19 & 10 \\
& bi-weekly $(\mathrm{n}=14)$ & 12 & 15 & 13 \\
weekly $(\mathrm{n}=7)$ & 7 & 10 & 6 \\
With additional data of $10 \%$ of the highest discharges & & & 3 \\
RMSE (\%) & monthly $(\mathrm{n}=30)$ & 12 & 11 & 5 \\
& bi-weekly $(\mathrm{n}=14)$ & 6 & 2 & \\
\hline
\end{tabular}




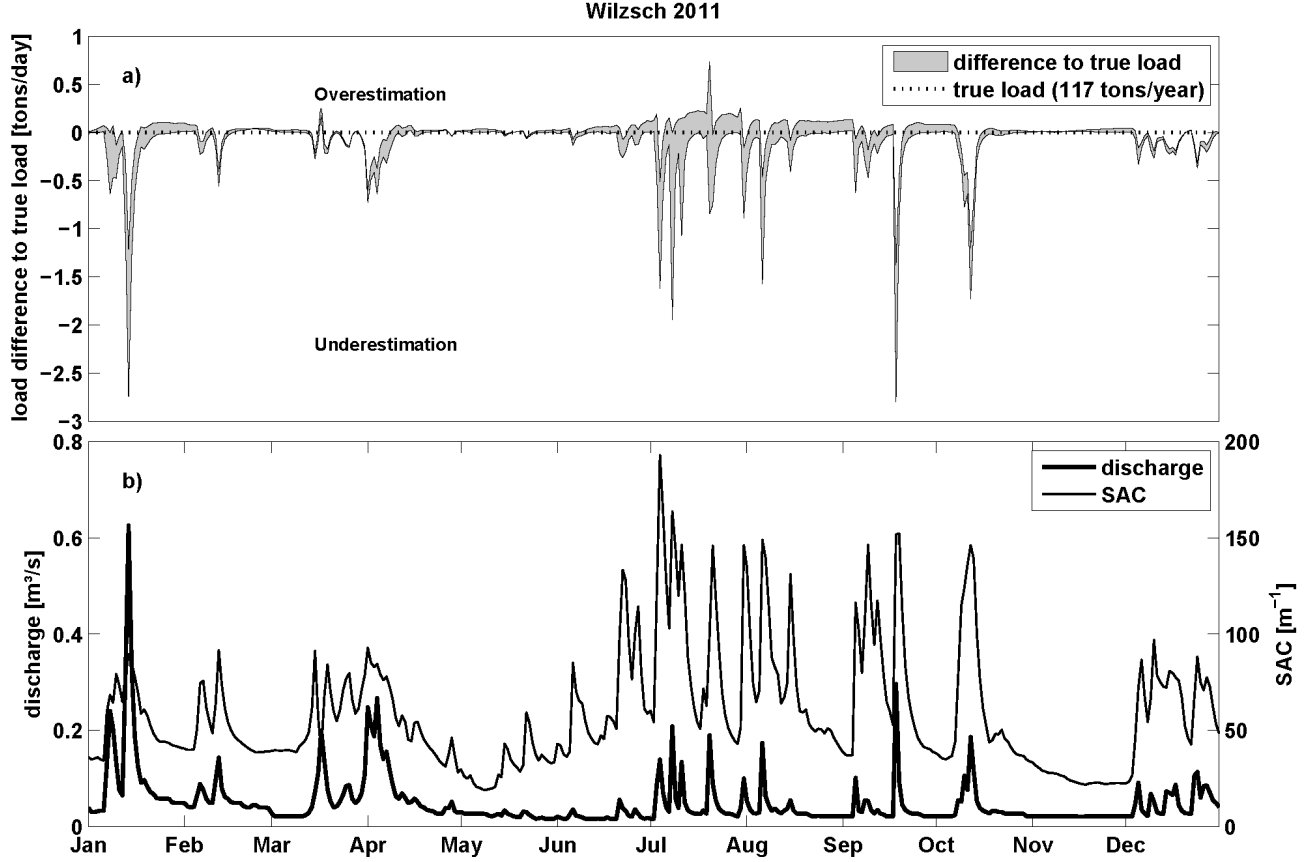

Fig. 1. Difference of estimated load and true load (a), course of discharge and SAC (b). The largest daily differences can be observed during discharge peaks (e.g. mid of January or during the summer period (June-August)). The figure a) represents an example for a monthly sampling rhythm in 2011. The upper and lower limit of the gray band in a) denotes the maximum and the minimum out of the 30 calculated loads overall (Eq. (2))

completed by additional sampling the $10 \%$ days of highest discharge is a good strategy for having load bias lower than $20 \%$. The latter is supported by the fact that the loads carried by the Wilzsch stream during $10 \%$ of the year (36 days) were $46 \%$, $53 \%$ and $48 \%$ for 2009, 2010 and 2011, respectively. However, additional efforts on DOC sampling are only useful, if discharges can be measured within small error ranges.

Acknowledgements. We thank Karin Freier, Anke Heiser and Ralf Sudbrack from The State Reservoir Administration of Saxony (Germany) for providing the SAC and discharge data. Michael Rode kindly commented on the manuscript.

\section{REFERENCES}

Battin, T.J., Kaplan, L.A., Findlay, S., Hopkinson, C.S., Marti, E., Packman, A.I., Newbold, J.D., Sabater, F., 2008. Biophysical controls on organic carbon fluxes in fluvial networks. Nature Geosci., 1, 95-100.

Cooper, D.M., Watts, C.D., 2002. A comparison of river load estimation techniques: application to dissolved organic carbon. Environmetrics, 13, 733-750.

Grayson, R., Holden, J., 2012. Continuous measurement of spectrophotometric absorbance in peatland streamwater in northern England: implications for understanding fluvial carbon fluxes. Hydrol. Process., 26, 27-39.

Grunewald, K., Scheithauer, J., 2010. Forst- und wasserwirtschaftliche Praxis unter Berücksichtigung naturschutzfachlicher Belange in Einzugsgebieten von Trinkwassertalsperren mit hohem Moor- und Fichtenforstanteil im oberen Erzgebirge (Beispiel: Carlsfeld). Landschaftsforschungszentrum e. V., Am Ende, 14, 01277 Dresden. (Report in German.)
Grunewald, K., Scheithauer, J., Sudbrak, R., Heiser, A., Freier, K., Andreae, H., 2011. Investigation of water and matter balance in catchments with degraded peat bogs in the Oberes Erzgebirge, barrage Carlsfeld. TELMA - Zeitschrift der Deutschen Gesellschaft für Moor- und Torfkunde, 41, 171-190. (In German.)

Hach-Lange, 2012. http://www.hach-lange.de/view/product/ EU-LXV418.99.50001/UVAS\%20plus\%20sc?productCode $=$ EU-LXV418.99.50001. Website accessed 20. 09. 2012. (In German.)

Johnes, P.J., 2007. Uncertainties in annual riverine phosphorus load estimation: Impact of load estimation methodology, sampling frequency, baseflow index and catchment population density. J. Hydrol., 332, 241-258.

Jollymore, A., Johnson, M.S., Hawthorne, I., 2012. Submersible UV-Vis spectroscopy for quantifying streamwater organic carbon dynamics: Implementation and challenges before and after forest harvest in a headwater stream. Sensors, 12, 3798-3813.

Moatar, F., Meybeck, M., 2005. Compared performances of different algorithms for estimating annual nutrient loads discharged by the eutrophic River Loire. Hydrol. Process., 19, 429-444.

Rode, M., Suhr, U., 2007. Uncertainties in selected river water quality data. Hydrol. Earth Syst. Sci. 11, 863-874.

Tian, Y.Q., Wang, D., Chen, R.F., Huang, W., 2012. Using modeled runoff to study DOC dynamics in stream and river flow: A case study of an urban watershed southeast of Boston, Massachusetts. Ecol. Eng., 42, 212-222.

Vidon, P., Hubbard L.E., Soyeux E., 2009. Impact of sampling strategy on stream load estimates in till landscape of the Midwest. Environ. Monit. Assess., 159, 367-379.

Received 20 July 2012 Accepted 28 September 2012 